\title{
The Impact of Maternal Depression on the Child and How to Prevent and Heal
}

\author{
Paulina Ping \\ Universitas Pendidikan Indonesia \\ Bandung, Indonesia \\ paulinaping@student.upi.edu
}

\begin{abstract}
Happiness, healthy life are valuable for society. It devout, academic achievement which is everybody's dreams. In fact, we find the opposite, the depression and unfortunate. The statement above is not easy to achieve. This article will discuss the cause why it is so difficult to achieve and it seems that maternal depression can cause the development problem of the children, therefore it is needed to be solved. Media gives much information about postpartum mother who had depression. Thus we can find so many institutes do the wide open intervention for children who have a lot of problem because of the effect of maternal depression. Aspects that the writer cite in this article are: definition of maternal depression, who are having the most risk of got the vulnerable effect of maternal depression, solution or intervention for depressed mother and their children.
\end{abstract}

Keywords-maternal depression; children; development; solution

\section{INTRODUCTION}

In a number of journals that discussing the impact of the mother of depression, said that the impact of maternal depression can occur in children and can also occur in the family and the environment in which the mother of the depression stay or domiciled. Now the impact experienced by the children that were born from the mother of depression, including children become less developed especially in cognitive development and also make children tend to become closed or quiet. This article also explained the impact of the mother of the depression against their husbands and children, or family, said depression mother has made the atmosphere in the house to become less comfortable even tends to be less harmony.

For some researchers or the author of The Journal of the mother depression, they are using the methods of data collection and there is also the situation using the interview method directly or by phone. Discussed some things that related to the topic of thedepression mother, among others: what is meant by mother depression, mother symptoms depression, the approximate amount of maternal depression, and solutions or how to prevent the number of mothers affected by depression and finally the mothers and children also enjoy a happy life and harmony [1]. Mother of depression can be caused by several things such as various issues ranging from the lack of economy (poverty), to physical violence and sometimes even it could be experiencing physical violence from their husbands [1]

\section{MATERNAL DEPRESSION}

\section{A. Definition}

Depression is a serious public health problem [2]. Depression is a common psychological disorder among mothers of young children, with prevalence rates ranging from 8 to $12 \%$. The experience of living with a depressed mother has serious consequences for many children and increases their risk for a number of developmental and adjustment problems [3] Several definitions of maternal depression is an illness that interferes with normal functioning in everyday life. Depression hinders a person's ability to sleep, work, eat, and enjoy activities [4] Encompasses the range of depressive disorders that can affect mothers from the prenatal period to up to one year postpartum, including prenatal and postpartum depression, and postpartum psychosis. These disorders also frequently coincide with additional conditions and risk factors including other mental health disorders, substance abuse, chronic medical conditions, domestic violence, and poverty, which can exacerbate depressive symptoms [5], disorder during the postpartum period, epidemiological data show that $8 \%$ to $20 \%$ of women develop a clinically significant depressive state during the first year following a child's birth [6], during and after pregnancy, is increasingly recognized as a serious problem, not only for the affected mothers but for their children as well. That many mothers suffer from depressive symptoms is well known, but the mechanisms through which their depression impacts their offspring are only now being systematically explored [7]

\section{B. The symptoms of Maternal Depression}

The symptoms of maternal depression are low mood, fatigue, sleeping and eating problems, excessive and inappropriate guilt, and slow psychomotor functioning. feelings of being inadequate in their maternal role or unable to take care of the child, excessive anxiety, or specific fears concerning the child's health [6] 


\section{Impact on Children, Prevention, and Healing. Impact on Children}

Some of the impact of maternal depression are [1] on cognitive development in long term rather than transitory, although the numbers were small and the mothers were not assessed clinically in the intervening three years [8], maternal depression is associated with children's developmental problems including impaired socio-emotional, cognitive and behavioural functioning [9], contribute to levels of depression when these children become adults [10], effects the development of social emotional in the adulthood [11], may include brain activity changes, failure to thrive, low American Pediatric Gross Assessment Record (APGAR) scores, elevated stress responses, increased emergency room visits, decreased well-child-care visits, insecure parent-child relationship, developmental disturbances emotionally, cognitively, and behaviorally [12], brain architecture and persistent disruptions of their stress response systems [1] increased risk for a variety of psychiatric problems, including depression and behavioral disturbances, and they also have social, achievement deficits [3] and altered immune functioning in infants from five months to nine months [13], mental health, including behavioral problems. Among young children, maternal depression leads to both internalizing and externalizing behavior problems [14], fatigue, difficulty concentrating, or losing interest in daily activities - may influence a mother's ability to make and keep doctor's appointments for her children, notice health problems in children, and adhere to treatment regimes for sick children [14], Research on nonLatino populations has consistently shown that children of depressed mothers manifest elevated rates of depressive symptomatology and are at increased risk for externalizing and internalizing problems as well as attentional deficits and school performance problems [15], disrupts the architecture of the developing brain [16], outcomes in infancy, such as language and cognitive problems [17], poor cognition, social interaction and physical development and disruptive behaviour in the first year of life [18], child development, namely, the adequacy of maternal-child interactions in meeting the communication needs of children in their formative years [19], increased risk for emotional and behavioral disturbances [20], health [21]

\section{Prevention and Healing}

Prevention programs for maternal depression: Interdisciplinary interaction will result in attaining a profound understanding of the human person and help him/her to achieve lasting fulfilment by adequately paying attention to the transcendental, religious and spiritual needs [22] religion has proved to be immensely beneficial for holistic health and integral human development [22], having a good praying regulation [23] sharing [24] Parenting [2][25], daily exercise, feel thankfully, rileks [25] Evidence suggests that intensive therapies that focus on both mothers and their young children together can improve child outcomes [2], recent changes offer the opportunity to design and implement reforms that would increase the number of mothers who receive effective treatment. Moreover, there is strong evidence that in addition to benefiting mothers' wellbeing, these reforms would bolster children's emotional and social development and learninghelping families across the country rise out of poverty [13], parenting [26], appropriate counseling session and psychotherapy is crucial to increase their mental well-being [27], Awareness of any potential differences may help early childhood professionals who work with mothers with depression [19]

Healing programs: the first thing to do is getting know the sign of maternal depression and how to deal with, Cognitive therapy, spiritual belief, associating their mind to the wellness, remembering the calm and confidence associated with health and happiness, contemplation, simple attitude of prayerfulness and a feeling of empathy, caring, and compassion for the entity in need, seemed to set the stage for healing [28] sharing [24], Treating maternal depression is crucial to improving parenting and getting children's development back on track for school and adult success, including escaping poverty. There is strong evidence that a variety of safe and effective tools exist for treating adults with depression, including pharmacotherapies, psychotherapies, behavioral therapies, and alternative medicines. Both medication and cognitive behavioral therapies, with modifications such as support for child care, have proven particularly effective for poor, minority women. Orienting the treatment to help mothers and fathers be effective parents is essential [13], Awareness of any potential differences may help early childhood professionals who work with mothers with depression [19]

\section{CONCLUSION}

Emphasizing this maternal depression issue could raise the caution of the caregiver who is capable of being the social support for the mother and the child who are in this depressed situation. Hopefully with continuously raised the issue of maternal depression is, the more open the mother to preserve the health of themselves, especially in their children, so that in the future their children were able to experience a happy life and enjoy the beauty of life. But in addition the mother depression may increasingly be open to run the steps for healing as well as running the preventive measures wich are holistic health, sharing, parenting [24][25], and having a good praying regulation.

\section{Acknowledgment}

Thanks and gratitude I convey unto the Lord for all the blessings he has given me so that I can finish this article properly. Thanks also to Sr. Maria and the sisters in the community who have delighted in providing any form of support, lecturers who've shared knowledge, friends in the Santa Angela Campus and the campus, and a fellow with the way each has been giving support so that this article can be finished well. 


\section{References}

[1] J. B. Richmond and C. Health, "Maternal Depression Can Undermine the Development of Young Children: Working Paper No. 8."

[2] C. R. Ronzio and S. J. Mitchell, "The Highs and Lows of Maternal Depression : Cluster Analysis of Depression Symptoms in a Sample of African American Women," vol. 58, no. 7, pp. 887-892, 2010.

[3] M. C. Lovejoy, P. A. Graczyk, E. O. Hare, and G. Neuman, "MATERNAL DEPRESSION AND PARENTING BEHAVIOR : A META-ANALYTIC REVIEW,” vol. 20, no. 5, pp. 561-592, 2000 .

[4] L. Tystahl, "Effects of maternal depression and cognitive readiness to parent on children $\hat{\mathrm{a}} \mathrm{e}^{\mathrm{TM}} \mathrm{s}$ social emotional outcomes," 2011.

[5] C. Catalyst and C. Hill, "Maternal Depression: Implications for Parents and Children and Opportunities for Policy Change Introduction Prevalence of Depression among Mothers with Infants Consequences of Untreated Depression."

[6] F. Frascarolo and J. Despland, "Family Alliance as a Moderator of the Link Between Maternal Postpartum Depression and Child Symptoms Assessed by Both Parents," 2014.

[7] B. G. K. Fritz, "Treating maternal depression to promote child development: A 'two-fer,"” no. December, 2013.

[8] S. R. Cogill, H. L. Caplan, H. Alexandra, and K. A. Y. M. Robson, "Impact of maternal postnatal depression on cognitive development of young children,” vol. 292, no. May, pp. 1165-1167, 1986.

[9] "Maternal depression," no. October, 2010

[10] N. Wray, "Maternal depression and family adversity: Linked pathways to offspring depression?," J. Psychiatr. Res., 2017.

[11] J. P. Shonkoff, "The Foundations of Lifelong Health Are Built in Early Childhood," Harvard Univ. Cent. Dev. Child, pp. 1-32, 2010.

[12] A. Manuscript and M. Depression, "NIH Public Access," vol. 37, no. 4, pp. 253-261, 2013.

[13] B. S. Schmit, O. Golden, and W. Beardslee, "Maternal Depression : Why It Matters to an Anti-Poverty Agenda for Parents and Children Maternal Depression : Why It Matters to Your Work," no. March, 2014

[14] K. Turney, "Maternal Depression and Childhood Health Inequalities," 2011

[15] E. Aisenberg, P. K. Trickett, and W. Saltzman, "An Examination of Mediation Among Immigrant Latino Mothers and Their Adolescent Children Exposed to Community Violence," pp. 1227-1249, 2016.
[16] N. Scientific, "Stress Disrupts the Architecture of the Developing Brain.”

[17] S. M. Petterson and A. B. Albers, "Effects of Poverty and Materna Depression on Early Child Development," vol. 72, no. 6, pp. 17941813, 2001.

[18] L. A. Quevedo et al., "Child : The impact of maternal post-partum depression on the language development of children at 12 months," pp. $420-425,2011$.

[19] D. A. Hwa-froelich, C. A. L. Cook, and L. H. Flick, "Maternal Sensitivity and Communication Styles," pp. 44-66, 2008.

[20] I. Features, "Maternal Depression and Motherese: Temporal and Intonational Features Author ( s ): Barbara A . Bettes Published by: Wiley on behalf of the Society for Research in Child Development Stable URL : http://www.jstor.org/stable/1130275 Accessed : 06-042016 ," vol. 59, no. 4, pp. 1089-1096, 2016.

[21] T. Field, "NIH Public Access," vol. 33, no. 1, pp. 1-9, 2011.

[22] J. Vayalilkarottu, "Holistic health and well-being: A psychospiritual / religious and theological perspective," Asian J. Psychiatr., vol. 5 , no. 4 , pp. $347-350,2018$.

[23] A. B. Newberg, N. A. Wintering, D. B. Yaden, M. R. Waldman, and J. Reddin, "Journal of Physiology - Paris A case series study of the neurophysiological effects of altered states of mind during intense Islamic prayer," J. Physiol. PARIS, pp. 1-7, 2015.

[24] A. Coghlan, "Diseases eat into world chocolate supplies," New Sci., vol. 202 , no. 2703 , p. $9,2009$.

[25] D. S. Shaw, A. Connell, T. J. Dishion, M. N. Wilson, and F. Gardner, "Improvements in maternal depression as a mediator of intervention effects on early childhood problem behavior," vol. 21, pp. 417-439, 2009.

[26] L. S. Abrams and L. Curran, "Maternal Identity Negotiations Among Low-Income Women With Symptoms of Postpartum Depression,” 2011.

[27] M. S. Mustaffa, M. S. Abu, A. Khan, and R. Ahmad, "Social Support During Pre - Natal And Post - Natal Stage : Influence On Maternal Depression And Mental Well - Being," vol. 143, pp. 417422, 2014.

[28] N. Rosila and N. Yaacob, "Cognitive therapy approach $f$ from Islamic psycho-spiritual conception," Procedia - Soc. Behav. Sci., vol. 97, pp. 182-187, 2013. 